\title{
The doripenem serum concentrations in intensive care patients suffering from acute kidney injury, sepsis, and multi organ dysfunction syndrome undergoing continuous renal replacement therapy slow low-efficiency dialysis
}

This article was published in the following Dove Press journal:

Drug Design, Development and Therapy

23 October 2014

Number of times this article has been viewed

\section{Andrzej Wieczorek \\ Andrzej Tokarz \\ Wojciech Gaszynski \\ Tomasz Gaszynski}

Department of Anesthesiology and Intensive Therapy, Medical University of Lodz, Lodz, Poland
Correspondence: Andrzej Wieczorek Department of Anaesthesiology and Intensive Therapy, Medical University of Lodz, ul. Kopcinskiego 22, 90-I53

Lodz, Poland

Email rangen@vp.pl

\begin{abstract}
Doripenem is a novel wide-spectrum antibiotic, and a derivate of carbapenems. It is an ideal antibiotic for treatment of serious nosocomial infections and severe sepsis for its exceptionally high efficiency and broad antibacterial spectrum of action. Doripenem is eliminated mainly by the kidneys. In cases of acute kidney injury, dosing of doripenem depends on creatinine clearance and requires adjustments. Doripenem is eliminated during hemodialysis because its molecular weight is 300-400 Da. The aim of this study was to establish the impact of continuous renal replacement therapy (CRRT) slow low-efficiency dialysis (SLED) on doripenem serum concentrations in a population of intensive-therapy patients with life-threatening infections and severe sepsis. Ten patients were enrolled in this observational study. Twelve blood samples were collected during the first administration of doripenem in a 1-hour continuous infusion while CRRT SLED was provided. Fluid chromatography was used for measurement of the concentration of doripenem in serum. In all collected samples, concentration of doripenem was above the minimum inhibition concentration of this antibiotic. Based on these results, we can draw the conclusion that doripenem concentration is above the minimum inhibition concentration throughout all of CRRT. The dosing pattern proposed by the manufacturer can be used in patients receiving CRRT SLED without necessary modifications.
\end{abstract}

Keywords: AKI, antibiotic, antimicrobial therapy, carbapenem, CRRT, infection, MODS, SLED

\section{Introduction}

Doripenem, like other carbapenems, is an ideal antibiotic for treatment of serious nosocomial infections and severe sepsis for its exceptionally high efficiency and broad antibacterial spectrum of action. In microbiological studies, it showed high activity against some bacterial strains (eg, Pseudomonas aeruginosa, Klebsiella sp.) responsible for ventilator-associated pneumonia (VAP). ${ }^{1}$ Clinical studies showed similar efficacies of doripenem and meropenem in the population of febrile patients with acute hematologic diseases. ${ }^{2}$ A randomized controlled trial comparing a 7-day course of doripenem to a 10-day course of imipenem/cilastatin for VAP due to Gram-negative bacteria infection found no significant differences in efficacy or mortality rate. ${ }^{3}$ Thus, doripenem is an important antimicrobial chemotherapeutic agent, especially for patients suffering from serious infections and severe sepsis caused by Gram-negative species. An analysis of 
patients with concurrent bacteremia and either nosocomial pneumonia, complicated intra-abdominal infection, or complicated urinary tract infection from six Phase III clinical trials demonstrated similar cure rates and clearance of bacteremia in patients treated with doripenem and comparator agents. ${ }^{4}$ In the US CAPITAL (Carbapenem Antimicrobials Pseudomonas Isolate Testing At regional Locations) 2010 surveillance program, doripenem was found to be the most active carbapenem agent against $P$. aeruginosa $(88.6 \%$ isolates susceptible versus $78.1 \%$ for imipenem and $84.6 \%$ for meropenem). ${ }^{5}$

Doripenem is mainly eliminated by kidneys; thus, the dose adjustment in cases of renal failure is a necessary therapeutic modification. However, if patients are treated with the use of renal replacement therapy (RRT) technique, the drug elimination may increase significantly, and adequate dosage and administration is unclear. ${ }^{6,7}$ The growing role and increasing importance of RRT is based on the evidence that the early use of the procedure may limit mortality rate and improve outcome. ${ }^{8}$ The molecular weight cutoffs of commonly used filter membranes are much higher than the molecular weight of unbound particles of antibiotics. Thus, the free fraction of antibiotics should be eliminated during RRT, with speed depending on modality and form of individually planned procedures. Additionally, the subsequent occurrence and growth of other elements of multi organ dysfunction syndrome (MODS) disturbances may significantly affect the pharmacokinetics of many drugs, among them doripenem and other antibiotics. ${ }^{9}$ In such situations there is an important risk that increased RRT antibiotic clearance might create a competing morbidity, secondary to ineffective treatment of serious infections. ${ }^{10}$ There are many continuous renal replacement therapy (CRRT) modes available, but for patients in severe sepsis slow low-efficiency dialysis (SLED) seems to be a good option. The main advantages of SLED technique for such patients are hemodynamic stability and effective reduction of the fluid overload.

The aim of this study was to establish the impact of SLED used as a CRRT on doripenem serum concentrations in a population of intensive-therapy patients with life-threatening infections and severe sepsis.

\section{Materials and methods}

After obtaining the ethics committee approval, the study began. The inclusion criteria were: severe sepsis, acute kidney injury (AKI) and failure (defined following RIFLE and AKIN criteria), and infection with bacteria sensitive to doripenem. The sensitivity was confirmed by antibiogram. Exclusion criteria were: lack of consent, possible allergy to carbapenems, and administration of carbapenem antibiotics prior to the study because they may interfere with chromatography measurement - the chemical structure of doripenem is similar to other carbapenems so it could affect the results of measurement of concentration of drug in serum. All included patients required RRT. The method used for this trial was SLED with Genius apparatus with high-flux filter. The dose of hemodialysis was individually determined, but generally all patients received one standardized session of RRT for trial: blood flow $120-130 \mathrm{~mL} / \mathrm{min}$ and ultrafiltration $2,000-7,000 \mathrm{~mL} / 24$-hour (mean ultrafiltration 4,500 mL/24-hour). A standard dialysis fluid container capacity was $90 \mathrm{~L}$, and during a 24-hour session the measured total fresh dialysate circulating volume was 180 L. For the study, a new session was always commenced with fresh dialysate fluid.

The study protocol was as follows: sample 0 was collected before administration of drug; the RRT session was started with a new container; doripenem was administrated in a 1-hour infusion using an automated syringe following recommendations of the manufacturer. Sample 1 was collected from separate intravenous access 30 minutes after commencing the drug administration during CRRT. Next, samples 2-8 were collected in 30-minute intervals for the first 4 hours, and samples 9-12 every 1 hour for the next 4 hours. Summary time of sample collection was 8 hours. Only the first administration of doripenem was evaluated.

Every sample was prepared following instruction for the fluid chromatography measurement: the blood samples were collected to vacutainer heparinized blood collection tube. Collected blood samples were centrifuged for 10 minutes $(1,000 \times g)$ at a temperature of $4^{\circ} \mathrm{C}$. Zero point five milliliters of serum was then taken into $2 \mathrm{~mL}$ Eppendorf testing tubes and mixed with $0.5 \mathrm{~mL}$ of $1 \mathrm{~mol} / \mathrm{L} 3$-(N-morpholino)propanesulfonic acid buffer. Then, it was stored in a $-40^{\circ} \mathrm{C}$ refrigerator until the time of analysis. The analysis was performed on a fluid chromatography machine. Blood samples were subjected to spectrophotometric detection using ultrafast performance liquid chromatography using the ACQUITY ultrafast performance liquid chromatography (BEH C-18, 100x2,1 mm; Waters Inc., MA, USA) column to determine the concentrations of doripenem.

Statistical analysis was performed using Microsoft Office Excel Package (Microsoft Corporation, Redmond, WA, USA).

\section{Results}

Department of Anesthesiology and Intensive Therapy at Barlicki University Hospital is referral for the regions intensive care unit (ICU) which has 13 beds. The severe sepsis cases are admitted from the area of Lodz city and its surroundings. There are five Genius machines for CRRT. The mean number of patients admitted to this ICU was 304 
per year, mean time of treatment was 9.8 days, and mean mortality rate was $64.1 \%$.

The study was commenced in 2008. In 2008, a total of 309 patients were admitted to this ICU; in 2009, 303 patients were admitted; and in 2010, 306 patients were admitted. The number of performed SLED/CVVHD procedures was 168 (in 2008), 222 (in 2009), and 231 (in 2010) in a total of 78 patients. Forty-nine of them suffered from severe sepsis, but 39 required CRRT. Inclusion criteria (severe sepsis, MODS, AKI, and infection caused by bacteria sensitive to doripenem) as well as no carbapenem administration prior to the study was met by 16 patients. Finally, it was possible to include 14 adult patients (seven men and seven women) into the study. Complete data were collected for ten of the patients who met the inclusion criteria (six men and four women). Demographic data, scoring, and initial biochemical parameters (at the moment of commencing CRRT) are presented in Table 1. From ten patients, included into the study, nine died and one survived. In Table 2, reason for admission (main illness causing sepsis) and comorbidities are presented. All patients included suffered because of severe sepsis or septic shock secondary to diagnosed infections (mean serum c-reactive protein $236.9 \pm 92.8 \mathrm{mg} / \mathrm{L}$, mean serum procalcitonin $102 \pm 116.6 \mathrm{ng} / \mathrm{mL}$, white blood cell count $39.4 \pm 19.0 \mathrm{~g} / \mathrm{L}$, platelet blood count $66.1 \pm 56.8 \mathrm{~g} / \mathrm{L}$ ) and had need for advanced mechanical ventilation with the use of high fraction of inspired oxygen $(0.85 \pm 0.25)$ and catecholamine infusions. Additionally they all suffered because of significant acute nutrition disorders (with mean serum protein $41.75 \pm 14.37 \mathrm{~g} / \mathrm{L}$ ), which were resistant to applied alimentation therapy (supplemented both via

Table I Demographic data, ARF parameters at date of study, and length of stay at ICU

\begin{tabular}{ll}
\hline Parameter & $\begin{array}{l}\text { Value (mean } \pm \text { standard } \\
\text { deviation) }\end{array}$ \\
\hline Age & $56.2 \pm 10$ years \\
Urea (BUN) & $150.25 \pm 58.2 \mathrm{mg} / \mathrm{dL}$ \\
Creatinine & $4.64 \pm 2.4 \mathrm{mg} / \mathrm{dL}$ \\
RIFLE stage & Failure $(\mathrm{n}=9) /$ injury $(\mathrm{n}=\mathrm{I})$ \\
AKIN stage & $3(\mathrm{n}=9) / 2(\mathrm{n}=\mathrm{I})$ \\
APACHE II & $34.1 \pm 6.72$ \\
SOFA & $13.4 \pm 3.78$ \\
TISS 28 & $43.4 \pm 9.26$ \\
Length of stay in ICU & $14.8 \pm 11.4$ days \\
Need for mechanical ventilation & $13.8 \pm 6.85$ days \\
Need for catecholamine infusion & $12.9 \pm 5.32$ days \\
\hline
\end{tabular}

Abbreviations: AKIN, Acute Kidney Injury Network classification system; APACHE II, Acute Physiology, Chronic Health Evaluation II scoring system; ARF, acute renal failure; BUN, blood urea nitrogen; ICU, intensive care unit; RIFLE, Risk of renal failure, Injury to kidney, Failure of kidney function, Loss of kidney function and End-stage renal failure classification system; SOFA, Sequential Organ Failure Assessment scoring system; TISS 28, simplified Therapeutic Intervention Scoring System - 28 items.
Table 2 Main illness causing sepsis and comorbidities

\begin{tabular}{|c|c|c|c|}
\hline Main illness & $\begin{array}{l}\text { Number } \\
\text { of patients }\end{array}$ & Comorbidities & $\begin{array}{l}\text { Number } \\
\text { of patients }\end{array}$ \\
\hline $\begin{array}{l}\text { Acute } \\
\text { pancreatitis }\end{array}$ & 1 & DM & 3 \\
\hline Meningitis & 2 & Status post-CABG & 1 \\
\hline Pneumonitis & 3 & $\begin{array}{l}\text { Status post- } \\
\text { valvuloplasty }\end{array}$ & I \\
\hline Peritonitis & 3 & $\begin{array}{l}\text { Status post- } \\
\text { Whipple-operation }\end{array}$ & 1 \\
\hline \multirow[t]{3}{*}{$\begin{array}{l}\text { Urine system } \\
\text { inflammation }\end{array}$} & 1 & $\begin{array}{l}\text { Status post-spine- } \\
\text { operation }\end{array}$ & 1 \\
\hline & & IHD & I \\
\hline & & Nephrolithiasis & $\mathrm{I}$ \\
\hline
\end{tabular}

Abbreviations: CABG, coronary artery bypass grafting; DM, diabetes mellitus; IHD, intermittent hemodialysis.

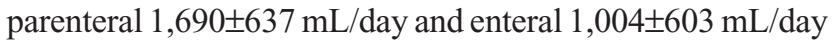
route, with maximum achieved serum protein $44.51 \pm 14.19$ $\mathrm{g} / \mathrm{L})$. Most of them had need for blood products transfusions (18.5 \pm 26.6 units) secondary to surgical procedures, gastrointestinal bleedings, and disseminated intravascular coagulation. Administered targeted antibiotic therapy with the use of doripenem led in three cases to selection of carbapenem-resistant species of Acinetobacter baumannii, which were treated with the use of intravenous and nebulized colistin (according to laboratory-tested susceptibility). The main causes of the high mortality rate were relatively late admission into the clinical ICU (all patients included were previously treated without effects in other wards, ICUs, and hospitals) and irreversible damage of at least one of the main vital organs (central nervous system, heart, or lungs) that was resistant to applied therapy.

The mean concentrations of doripenem in serum are presented in Figure 1. In all collected samples, concentration of doripenem was above minimum inhibition concentration of antibiotic (MIC) for doripenem.

\section{Discussion}

It is estimated that up to $40 \%$ of ICU patients may develop AKI and $5 \%$ of them will require RRT. The majority of them have infection and multiorgan dysfunction. Sepsis accompanied with AKI is an indication for CRRT. ${ }^{11} \mathrm{AKI}$ criteria are met when blood urea nitrogen exceeds $80 \mathrm{mg} / \mathrm{dL}$ or creatinine level is above $3 \mathrm{mg} / \mathrm{dL} .{ }^{11}$ All patients included in our study met the criteria of AKI and severe sepsis. They all suffered due to: respiratory failure (required mechanical ventilation), circulatory failure (required vasopressors and fluid therapy), and other systems disturbances (metabolic disorders, drop in platelet count and elevation of c-reactive protein and lactate levels). Most importantly, they had severe infection. This severe infection required adequate treatment 


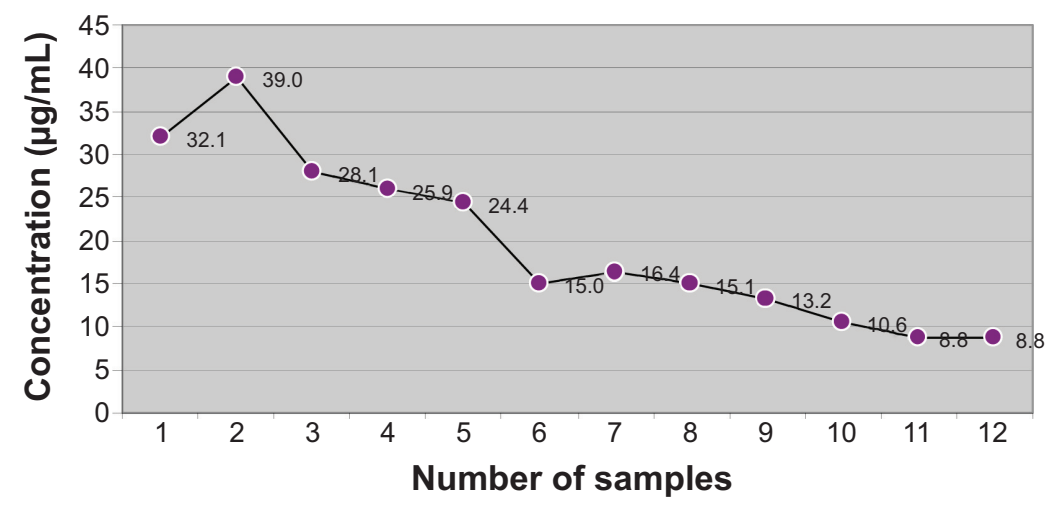

Figure I Mean concentration of doripenem in serum.

including antibiotic therapy. AKI was treated with the use of RRT. The best option for ICU patients, especially those suffering from cardiovascular instability, is CRRT because it has less effect on the cardiovascular system than standard hemodialysis provided as intermittent hemodialysis (IHD) and creates a much more effective method for water elimination, which is essential for avoiding massive fluid overload aggravating mortality rate. In cases of standard hemodialysis, the modification of drug dosage for many antibiotics is well described, but as for CRRT there are not many pharmacology studies and those available were performed on small groups of patients - for example, for carbapenems (imipenem), six patients were included for one method of CRRT. ${ }^{12}$ Available recommendations for antibiotics dosage during CRRT are based on very limited clinical data, and in many cases, those dosing recommendations are extrapolations from clinical experiences and known pharmacokinetic and pharmacodynamic properties. More clinical data are needed to support such extrapolations, and these recommendations should not supersede sound clinical judgment. ${ }^{13}$ So it is still not well-known how to modify doses of some antibiotics in patients with MODS, AKI, and sepsis undergoing CRRT. Because there are several methods of CRRT available it complicates the situation even more. It is indicated to measure levels of antibiotics in serum during therapy, as the best method of adjusting dosage, but this is not available in many hospitals because of the high level of costs and complicated procedures. The way of dosing antibiotics differs between IHD and CRRT. ${ }^{14}$ As mentioned before, methods of CRRT are also different; for example, continuous venovenous hemofiltration $(\mathrm{CVVH})$ will influence in different ways antibiotic concentration in serum compared to the SLED technique. Type of filter also plays an important role in elimination of antibiotics. In the case of all mentioned methods of RRT, extracorporeal elimination of drugs is different. In cases of patients treated in ICU, the situation is more complicated because of changes in pharmacology of drugs; for example, changes in albumin levels and their composition influences protein binding of drugs which is important for elimination fraction during RRT. ${ }^{14}$ Those changes in pharmacokinetics of drugs are connected with pathophysiology in the course of illness (for example, disseminated intravascular coagulation, endothelium leakage, changes in serum proteins, and acid-base balance disturbances) and interactions with drugs used for therapy. As a consequence, it is observed that changes in volume of distribution of water-soluble drugs, altered protein binding, levels of free fraction of drugs, and altered metabolism of drugs and other substances (including for example hormones, decreased clearance, and hyperdynamic circulation in early sepsis) may result in supranormal renal clearances ${ }^{15}$ All of this makes antibiotic therapy difficult in severely ill patients. Antibiotic therapy requires usage of algorithms of drug dosage and special formulas for modification. The general rule is that during CRRT, as it is less efficient than IHD, the drug dosage may not be changed. ${ }^{16}$ But still it was not proved in the case of CRRT SLED that this approach is correct. ${ }^{15}$ The molecular weight of the majority of antibiotics is lower than 1,500 Da (many of them have a molecular weight lower than $500 \mathrm{Da}$ ) and they are easily removed during extracorporeal elimination. Protein binding is very important because only the free fraction of antibiotics is removed during CRRT SLED. If protein binding is less than $80 \%$, the antibiotic is also easily eliminated. Clearance of most of antibiotics is high during CRRT, but in cases of CRRT SLED, because it is low-efficiency dialysis, the dosage may not be required to be modified. If extracorporeal elimination of drug is higher than $25 \%$, the modification in dosage may be necessary. If drug concentration in serum is lower than minimal bactericidal concentration (MBC), there is a serious risk of developing drug resistance of bacteria, so the aim of antibiotic dosing pattern must be keeping levels of antibiotic concentration in 
serum above MBC. Thus, for antibiotics with low toxicity, the overdosage during CRRT may be required to keep serum concentration above MBC. This is not proved for CRRT SLED. In a previously published study on antibiotic therapy during SLED among chronic stable patients, underdosing was common. ${ }^{17}$ But up to this moment there are no published studies on doripenem dosage in cases of critically ill patients undergoing CRRT SLED.

Doripenem is a novel wide-spectrum antibiotic and a derivate of carbapenems. It was introduced to clinical practice in 2005 in Japan, and in 2008 in Poland. In carbapenems, classification of doripenem is situated in group 2 together with meropenem and imipenem. ${ }^{18}$ Doripenem is especially useful in treatment of infections that are methicillin or vancomycin resistant. It is used in complicated intra-abdominal infections, complicated urinary-tract infections, severe community associated pneumonia, severe hospital-associated pneumonia, and VAP/intubated-associated pneumonia. ${ }^{19}$ Therefore, it is much needed in ICUs and has very good activity on isolates of $P$. aeruginosa (importantly, it has lower MIC90 than meropenem and imipenem). It provides less selection of carbapenem-resistant $P$. aeruginosa metallo-beta-lactamase and has lower toxic effect on the central nervous system. ${ }^{20,21}$ The pharmacological properties of doripenem are: half-life of 1 hour, low protein binding (8.1\%), high concentration of active form in serum, and it is stable toward dehydrogenase I. Thirty percent of the drug is metabolized and $70 \%$ is removed unchanged through kidneys within 24 hours. ${ }^{18}$ Like other carbapenems, doripenem has time-dependent pharmacokinetics/ pharmacodynamics $-\% \mathrm{~T}>\mathrm{MIC}$. The effectiveness is high with serum maximum concentration 4-5 times bigger than MIC and concentration above the MIC maintained through more than $40 \%$ of time between dosages. Doripenem may be administrated in a 1-hour infusion (three times $500 \mathrm{mg}$ ) or in prolonged 4-hour infusion (extended infusion dosing) which increases significantly $\% \mathrm{~T}>\mathrm{MIC} .{ }^{18}$ Maximum concentration of drug when dosed as mentioned reaches $23 \mu \mathrm{g} / \mathrm{mL}$. MIC for Enterobacteriaceae is $4 \mu \mathrm{g} / \mathrm{mL}$, and for resistant $P$. aeruginosa $16 \mu \mathrm{g} / \mathrm{mL} .^{22}$ In renal failure, dosing of doripenem depends on creatinine clearance and requires adjustments. ${ }^{23}$ Doripenem is eliminated during hemodialysis because its molecular weight is $300-400 \mathrm{Da}^{23}$ Standard filters used for CRRT SLED have pores of 1,200 Da size.

The studies on doripenem pharmacokinetics in patients undergoing CRRT showed that, depending on the procedure technique (CVVH versus CVVHD), administered dose removal varied from $38 \%$ to $29 \%$. Thus, doripenem dosage regimens for patients receiving CRRT need to be adjusted. ${ }^{23}$ Only a few studies involving critically ill patients treated with doripenem and receiving CRRT have been published up to this moment. Different populations and techniques of CRRT described in these studies may have an important impact on the results. Additionally the involved study populations were very small. Ohchi et al concluded that clearance via hemodiafiltration increases proportionally to the hemopurification rate. Thus, they suggested that doripenem dose should be increased to $1.0-1.5 \mathrm{~g} /$ day in critically ill adults when performing high-flow continuous hemodiafiltration. ${ }^{24}$ From the same center, Hidaka et al reported previous to this that the blood level of doripenem can be satisfactorily controlled by adjustment of doripenem dose and dosing interval, in accordance with residual renal function in critically ill patients receiving standard continuous hemodiafiltration. ${ }^{25}$ On the other hand, Samtani et al suggested that a reduction in doripenem dose will be needed for critically ill patients receiving $\mathrm{CVVH}$ or continuous venovenous hemodiafiltration. ${ }^{26} \mathrm{Up}$ to this moment, there are no studies published on the patients treated with doripenem and receiving CRRT in SLED mode. The results from our study may improve safety and efficacy of doripenem therapies in the population of critically ill patients.

\section{Conclusion}

Based on these results, we can draw the conclusion that concentration of doripenem is above MIC for this antibiotic throughout CRRT. The dosing pattern proposed by the manufacturer can be used in patients receiving CRRT SLED without necessary modifications.

\section{Acknowledgments}

We would like to thank Dr Slawomir Brzeznicki from the Department of Toxicology Medical University of Lodz, Poland, for preparing methods and performing fluid chromatography measurements. The trial was conducted with government grant number: N N403 185434. 507-16-027.

\section{Disclosure}

The authors report no conflicts of interest in this work.

\section{References}

1. Kozioł-Montewka M, Jaworska-Gromaszek I, Biernacka J, et al. [Review of the effectiveness of an empirical antibiotic therapy in suspected ventilator-associated pneumonia]. Anestezjol Intens Ter. 2011;43(3): 163-168. Polish.

2. Toya T, Nannya Y, Narukawa K, Ichikawa M, Kurokawa M. A comparative analysis of meropenem and doripenem in febrile patients with hematologic malignancies: a single-center retrospective study. Jpn J Infect Dis. 2012;65(3):228-232.

3. Kollef MH, Chastre J, Clavel M, et al. A randomized trial of 7-day doripenem versus 10-day imipenem-cilastatin for ventilator-associated pneumonia. Crit Care. 2012;16(6):R218. 
4. Rice DA, Kaniga K, Lee M, Redman R. Activity of doripenem versus comparators in subjects with baseline bacteraemia in six pooled phase 3 clinical trials. Int J Antimicrob Agents. 2013;41(4):388-392.

5. Morrow BJ, Pillar CM, Deane J, et al. Activities of carbapenem and comparator agents against contemporary US Pseudomonas aeruginosa isolates from the CAPITAL surveillance program. Diagn Microbiol Infect Dis. 2013;75(4):412-416.

6. Li AM, Gomersall CD, Choi G, Tian Q, Joynt GM, Lipman J. A systematic review of antibiotic dosing regimens for septic patients receiving continuous renal replacement therapy: do current studies supply sufficient data? J Antimicrob Chemother. 2009;64(5):929-937.

7. Eyler RF, Mueller BA; Medscape. Antibiotic dosing in critically ill patients with acute kidney injury. Nat Rev Nephrol. 2011;7(4): 226-235.

8. Karvellas CJ, Farhat MR, Sajjad I, et al. A comparison of early versus late initiation of renal replacement therapy in critically ill patients with acute kidney injury: a systematic review and meta-analysis. Crit Care. 2011;15(1):R72.

9. Morabito S, Pistolesi V, Maggiore U, Ficcadori E, Pierucci A. [Pharmacokinetics of antibiotics in continuous renal replacement therapies (CRRT)]. G Ital Nefrol. 2012;29(4):425-444.

10. Fissell WH. Antimicrobial dosing in acute renal replacement. $A d v$ Chronic Kidney Dis. 2013;20(1):85-93.

11. Jedynak M, Siemiatkowski A, Rygasiewicz K. Molecular basics of sepsis development. Anaesthesiol Inten Ther. 2012;44(4):221-225.

12. Fish DN, Teitelbaum I, Abraham E. Pharmacokinetics and pharmacodynamics of imipenem during continuous renal replacement therapy in critically ill patients. Antimicrob Agents Chemother. 2005;49(6): 2421-2428.

13. Trotman RL, Williamson JC, Shoemaker M, Salzer WL. Antibiotic dosing in critically ill adult patients receiving continuous renal replacement therapy. Clin Infect Dis. 2005;41:1159-1166.

14. Piskunowicz G. Antybiotykoterapia u chorych wymagających ciągłego leczenia nerkozastępczego z uwzględnieniem podstawowych aspektów farmakokinetyki antybiotyków u krytycznie chorych [Antimicrobial therapy in patients receiving continuous renal replacement therapy including pharmacokinetic aspects of antibiotic use]. Anestezjologia $i$ Ratownictwo. 2010;4:81-89. Polish.

15. Dufour D, Montravers P. Pharmacokinetics of antibiotics or antifungal drugs in intensive care units. Curr Infect Dis Rep. 2009;11:14-20.
16. Schetz M. Drug dosing in continuous renal replacement therapy: general rules. Curr Opin Crit Care. 2007;13:645-651.

17. Harris LE, Reaves AB, Krauss AG, Griner J, Hudson JQ. Evaluation of antibiotic prescribing patterns in patients receiving low-efficiency dialysis: opportunities for pharmacists. Int J Pharm Pract. 2013;21(1):55-61.

18. Cirillo I, Mannens G, Janssen C, et al. Disposition, metabolism, and excretion of $[14 \mathrm{C}]$ doripenem after a single 500-milligram intravenous infusion in healthy men. Antimicrob Agents Chemother. 2008;52(10):3478-3483.

19. Merchant S, Gast C, Nathwani D, et al. 2008. Hospital resource utilization with doripenem versus imipenem in the treatment of ventilatorassociated pneumonia. Clin Ther. 2008;30(4):717-733.

20. Jones RN, Huynh HK, Biedenbach DJ. Activities of doripenem (S-4661) against drug-resistant clinical pathogens. Antimicrob Agents Chemother. 2004;48:3136-3140.

21. Mushtaq S, Ge Y, Livermore DM. Doripenem versus Pseudomonas aeruginosa in vitro: activity against characterized isolates, mutants, and transconjugants and resistance selection potential. Antimicrob Agents Chemother. 2004;48:3086-3892.

22. Kim A, Banevicius MA, Nicolau DP. In vivo pharmacodynamic profiling of doripenem against Pseudomonas aeruginosa by simulating human exposures. Antimicrob Agents Chemother. 2008;52(7):2497-2502.

23. Cirillo I, Vaccaro N, Balis D, Redman R, Matzke GR. Influence of continuous venovenous hemofiltration and continuous venovenous hemodiafiltration on the disposition of doripenem. Antimicrob Agents Chemother. 2011;55(3):1187-1193.

24. Ohchi Y, Hidaka S, Goto K, et al. Effect of hemopurification rate on doripenem pharmacokinetics in critically ill patients receiving highflow continuous hemodiafiltration. Yakugaku Zasshi. 2011;131(9): 1395-1399.

25. Hidaka S, Goto K, Hagiwara S, Iwasaka H, Noguchi T. Doripenem pharmacokinetics in critically ill patients receiving continuous hemodiafiltration (CHDF). Yakugaku Zasshi. 2010;130(1):87-94.

26. Samtani MN, Vaccaro N, Cirillo I, Matzke GR, Redman R, Nandy P. Doripenem dosing recommendations for critically ill patients receiving continuous renal replacement therapy. ISRN Pharmacol. 2012;2012: 782656 .
Drug Design, Development and Therapy

\section{Publish your work in this journal}

Drug Design, Development and Therapy is an international, peerreviewed open-access journal that spans the spectrum of drug design and development through to clinical applications. Clinical outcomes, patient safety, and programs for the development and effective, safe, and sustained use of medicines are a feature of the journal, which

\section{Dovepress}

has also been accepted for indexing on PubMed Central. The manuscript management system is completely online and includes a very quick and fair peer-review system, which is all easy to use. Visit http://www.dovepress.com/testimonials.php to read real quotes from published authors. 